\title{
Setting a research agenda for medical overuse
}

\section{Citation}

Morgan, D. J., S. Brownlee, A. L. Leppin, N. Kressin, S. S. Dhruva, L. Levin, B. E. Landon, et al. 2015. "Setting a research agenda for medical overuse." BMJ : British Medical Journal 351 (1): h4534. doi:10.1136/bmj.h4534. http://dx.doi.org/10.1136/bmj.h4534.

\section{Published Version}

doi:10.1136/bmj.h4534

\section{Permanent link}

http://nrs.harvard.edu/urn-3:HUL.InstRepos:22856952

\section{Terms of Use}

This article was downloaded from Harvard University's DASH repository, and is made available under the terms and conditions applicable to Other Posted Material, as set forth at http:// nrs.harvard.edu/urn-3:HUL.InstRepos:dash.current.terms-of-use\#LAA

\section{Share Your Story}

The Harvard community has made this article openly available.

Please share how this access benefits you. Submit a story.

Accessibility 


\title{
Setting a research agenda for medical overuse
}

Although overuse in medicine is gaining increased attention, many questions remain unanswered. Dan Morgan and colleagues propose an agenda for coordinated research to improve our understanding of the problem

\author{
Daniel J Morgan associate professor ${ }^{1}$, Shannon Brownlee writer $^{2}$, Aaron L Leppin postdoctoral \\ research fellow ${ }^{3}$, Nancy Kressin professor ${ }^{4}$, Sanket S Dhruva research fellow ${ }^{5}$, Les Levin professor ${ }^{6}$, \\ Bruce E Landon professor ${ }^{7}$, Mark A Zezza vice president ${ }^{8}$, Harald Schmidt assistant professor ${ }^{9}$, \\ Vikas Saini president ${ }^{10}$, Adam G Elshaug Adam G Elshaug, Associate Professor and HCFRF \\ Principal Research Fellow and, Senior Fellow ${ }^{1112}$
}

\begin{abstract}
${ }^{1}$ Epidemiology, and Public Health, Veterans Affairs Maryland Healthcare System, University of Maryland School of Medicine, 685 W Baltimore St, Baltimore, MD 21201, USA; ${ }^{2}$ Lown Institute, Dartmouth School of Medicine, Boston, MA, USA; ${ }^{3}$ Knowledge and Evaluation Research Unit, Mayo Clinic, MN, USA; ${ }^{4}$ Boston VA and Boston University, Boston, MA, USA; ${ }^{5}$ Yale University and New Haven VA, New Haven, CT, USA; ${ }^{6}$ University of Toronto, Toronto, Ontario, Canada; ${ }^{7}$ Department of Health Care Policy, Beth Israel Deaconess Medical Center, Boston, MA, USA; ${ }^{8}$ Lewin Group's Federal Health And Human Services Practice, Washington, DC, USA; ${ }^{M}$ Medical Ethics and Health Policy, University of Pennsylvania, Philadelphia, PA, USA; ${ }^{10}$ Lown Institute, Harvard Medical School, Brookline, MA, USA; ${ }^{11}$ Menzies Centre for Health Policy, Sydney School of Public Health, University of Sydney, Australia; ${ }^{12}$ Lown Institute, Brookline, MA, USA
\end{abstract}

Overuse of medical services is common. ${ }^{1-5}$ In the United States, overuse represents as much as $30 \%$ of provided services ${ }^{5-9}$ and has been associated with worse outcomes and death. ${ }^{6}{ }^{10}$ The problem has existed for decades, ${ }^{1-12}$ but despite heightened recognition in recent years ${ }^{13-18}$ many gaps remain in our basic understanding of its scope, drivers, and potential for harming patients physically, mentally, and financially. Recent efforts on overuse include a joint statement by the American Board of Internal Medicine and Academy Health calling for improved definitions of medical overuse, ${ }^{19}$ and the Robert Wood Johnson Foundation recommended changes in state policy to reduce overuse. $^{20}$

Although the Agency for Healthcare Research and Quality (AHRQ) sponsored a report on medical overuse in 2009, this report did not delineate a framework for research. ${ }^{21}$ Research into overuse remains poorly coordinated and terms such as overuse, overdiagnosis, and low value care are all used to describe various interpretations of the concept. Without a common language or conceptual framework to connect research efforts and objectives, understanding of overuse will remain fragmented and limit our ability to make healthcare safer, less expensive, and more patient centered. Calls have been made for a research agenda. ${ }^{22}{ }^{23}$ This article provides a conceptual framework organizing the current research on overuse and formulating a research agenda. It reflects the consensus opinions of a working group of clinicians and researchers convened by the Lown Institute in December 2013.

\section{What do we know about overuse? Definitions}

The Institute of Medicine and others have defined overuse as "care in the absence of a clear medical basis for use or when the benefit of therapy does not outweigh risks." ${ }^{24}$ Closely related terms for overuse, often used as synonyms include overutilization, overmedicalization, and low value care. ${ }^{25}$ Other related concepts include overdiagnosis - the diagnosis of conditions that will never cause symptoms or harm during a patient's lifetime ${ }^{26}$ —and overtreatment - treatment that "according to sound science and the patient's own preferences, cannot possibly help." ${ }^{\prime 9}$ Figure $1 \Downarrow$ shows the relation between overdiagnosis, overtreatment, and overuse.

\section{Frequency of overuse}

Estimates of the scope of overuse vary from $10 \%$ to $30 \%$ of all care depending on the definition and method used (surveys of physicians $^{27} 28$ or patients ${ }^{6}$ or claims data ${ }^{7-29}$ ). Claims data have been used in "top down" approaches to identify geographic regions that use more surgery, hospitalization, and medical care. Such excess care has been associated with higher risk adjusted mortality. ${ }^{10-35}$ Recently, administrative data have been used to measure use of "do not do" practices. ${ }^{29}$ Most articles on overuse have examined outcomes that follow screening or diagnostic tests or discrete treatments. ${ }^{1-36}$ These investigations have identified potential overuse and established an evidence based 
case for reversing standard practice, or "de-implementation" in many areas of medicine such as the routine use of proton pump inhibitors ${ }^{37}$ surgery for various orthopedic conditions, ${ }^{38}$ estrogen replacement therapy, ${ }^{39}$ vertebroplasty, ${ }^{40}$ and inappropriate cardiac catheterizations. ${ }^{41}$ Recognition of such overuse requires the ability to identify when current evidence shows an intervention offers little or no benefit. ${ }^{42}$ Recent efforts to define overuse in cancer screening have identified the best methods to quantify overuse. $^{43}$

\section{Factors promoting overuse}

Many factors contribute to overuse (table $\Downarrow$ ) ${ }^{44}{ }^{45}$ Some relate primarily to patients, others to providers. Some factors relate more to intrinsic (patient or provider beliefs) and others to extrinsic pressure (related to healthcare systems). The relative importance of different causes of overuse is unknown.

\section{Effect of overuse}

The full effect of overuse on patients and health systems remains unknown. ${ }^{67}$ Clear patient harms have been identified from practices such as screening for breast, prostate, and thyroid cancer. ${ }^{68}{ }^{69}$ Similarly, magnetic resonance imaging for uncomplicated back pain can lead to surgery that poses net harm to patients. ${ }^{1}$ The risk of harm from overuse varies depending on the disease, its treatment, and the rate of overuse of the therapy. Unnecessary treatment burden (the activities required of patients to access and use care and navigate complex healthcare systems) is an additional negative consequence of overuse. $^{70} 71$

\section{Strategies to mitigate overuse}

Various approaches focusing on patients, providers, or system changes have been used in an attempt to limit overuse and have had varying success. Efforts to promote patient engagement, such as shared decision making, may reduce overuse. ${ }^{30-75}$ At the provider level, some clinical practice guidelines have become less aggressive in their treatment recommendations. ${ }^{76-78}$ Provider groups have also developed lists of clinical interventions that offer little net benefit (low value lists). ${ }^{13-40}$ Expanded understanding of the number needed to treat (NNT) has been proposed as a way to discuss overtreatment. ${ }^{79}$

At the system level, tools to limit overuse may include constraining resources through regulatory mechanisms such as Certificates of Need and insurance mandated preapprovals; regulating access to testing and treatment ${ }^{80}{ }^{81}$; global payment contracts (such as accountable care organizations) or strategies that increase patient cost sharing (such as high deductible health plans); changing reimbursement and care models to prioritize primary care; and robust assessment for new and existing medical technology. The effect of such changes on overuse, however, is largely understudied. ${ }^{51}$

\section{Research agenda for medical overuse}

Although definitions related to overuse and understanding of its frequency and causes have advanced, we still need research to answer fundamental questions related to overuse to improve patient care (box). Below we discuss these in more detail.

\section{Measure the frequency of overuse}

Develop agency(ies) to monitor overuse of diagnoses and treatments-Frequency of overuse has generally been identified retrospectively in only a few specific clinical areas. Given the importance of overuse, development of national agencies (or initially, branches within an agency) with authority similar to the US or European Centers for Disease Control and Prevention is a priority to monitor for "outbreaks" in use of diagnostic and treatment methods and variation in routine care. Surveillance of diagnostic billing codes and use of tests and therapies could be developed with appropriate methods for defining rates that account for changes in costs, reimbursements, and new tests. Such agencies could provide real time monitoring as well as annual descriptions of changes in rates of overuse along with potential contributing factors.

Define the scope of overdiagnosis and overtreatment-Although frequent overdiagnosis has been well described in cancer screening programs ${ }^{2-82}$ the overall frequency of inappropriate testing, overdiagnosis, and false positive results (and subsequent overtreatment) in other contexts is not well described (such as in ambulatory care or hospital medicine). Full assessment of the problem of overuse is another priority and would likely best be done using observational methods and patient level or administrative data.

\section{Capture clinical information in administrative data to allow} better assessment of overuse-Large scale measurement of overuse requires better means of evaluating administrative data. Current analysis of administrative data is retrospective and usually does not include sufficient clinical detail to assess appropriateness of care. ${ }^{29}$ Real time administrative data with better methods for risk adjustment and understanding geographic variation are needed..$^{34}$

\section{Identify factors promoting overuse}

Identify the most important drivers of overuse-Although many factors contribute to overuse (table $\downarrow$ ), there has been little exploration of the relative importance of these causes, how they interact, or the potential value of changing any single factor (such as malpractice tort reform or changes in reimbursement). Research should attempt to rank the relative importance of factors contributing to overuse. This would likely entail quasiexperimental analyses of changes in policies that relate to overuse.

Understand and communicate limitations in diagnostic testing-While diagnostic testing is essential to medicine, ${ }^{83-85}$ understanding of pretest probability, the frequency of false positives results, overdiagnosis, incidental findings, and subsequent treatment cascades, and a general approach to managing such results is needed. Ultimately, studies of tests that go beyond sensitivity or specificity and evaluate their impact on patient outcomes are needed. ${ }^{86}{ }^{87}$ Methods for such studies include cohort, quasiexperimental, and randomised trial approaches and economic analyses.

Explore how clinical uncertainty and cognitive biases may lead to overuse-Uncertainty is inherent in medicine and is a driver of overuse. ${ }^{52}{ }^{84}$ We have limited understanding, however, of how providers experience uncertainty and how this affects clinical decisions. Research using surveys and qualitative and quasiexperimental approaches is needed to evaluate how uncertainty and cognitive biases result in clinical decisions. ${ }^{87}$

\section{Measure the effect of overuse}

Study the physical and psychological harm of overuse on patients-Much of the research on harm from overuse has focused on populations and used administrative data, which cannot quantify many types of harm. ${ }^{10}$ Patient level clinical studies are needed to describe the specific physical, psychological, and economic harms that occur from overuse and the frequency of these harms. ${ }^{66-88}$ 


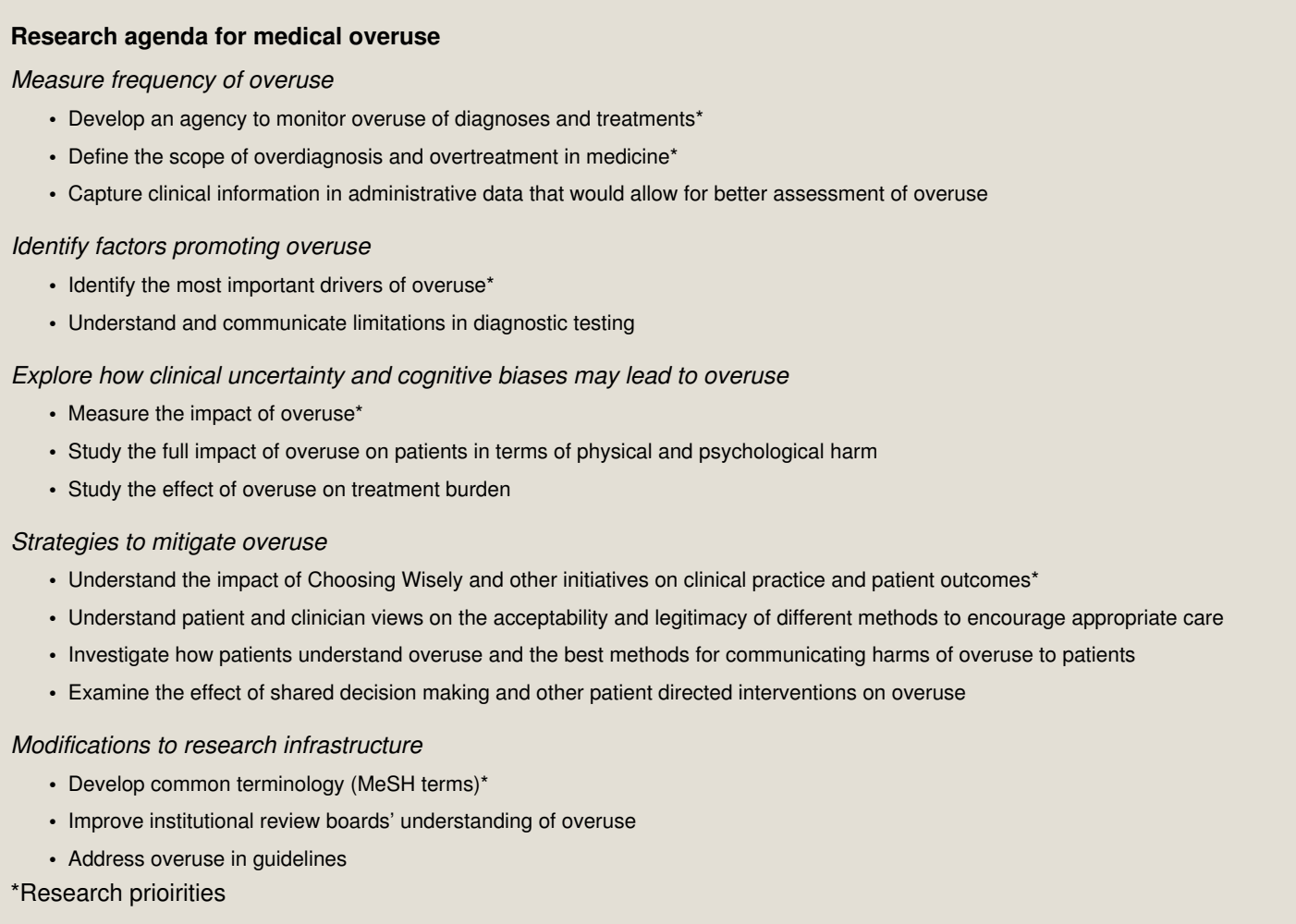

Study the effect of overuse on treatment burden-Further understanding of how patients experience treatment burden is also needed, along with quantification of its effect and how to lessen treatment burden in clinical practice. A more complete description of the negative consequences of overuse at a patient level could lead to metrics for interventional trials or performance improvement. Methods to examine harms and treatment burden will likely include cross sectional, retrospective, prospective cohort, and qualitative studies.

\section{Strategies to mitigate overuse}

Understand the effect of low value lists on clinical practice and patient outcomes-Although Choosing Wisely, the most publicly visible effort to limit overuse, ${ }^{18-89}$ has publicized the problem, its impact on patient care is not well described. This should be studied, probably in cross sectional and cohort studies with patient level or administrative data.

Understand patient views on the acceptability and legitimacy of different methods to encourage appropriate care-The concept of overuse implies setting limits on care, which may evoke concerns about rationing. Various policies are available to discourage overuse, such as ceasing to pay for low value interventions, and we need to assess the short and long term effectiveness and acceptability of both established and novel approaches. Surveys and qualitative methods will likely be most useful.

Investigate how patients understand overuse and the best methods for communicating its harms-If and when patients understand overuse is not well understood. Likewise, we do not know how patient expectations lead to overuse and which health beliefs create expectations for overuse. Studies are needed to determine the best methods to communicate with and educate patients on overuse in a way that will affect their decisions. Methods will likely include qualitative studies and quasiexperimental work. focused interventions on overuse-Though shared decision making is often invoked as means of reducing overuse, its effect is generally not known and merits study in qualitative and quasiexperimental research or randomized trials.

\section{Modifications to research infrastructure}

Create common terminology-Appropriate MeSH terms and keywords for searches in PubMed and other engines are needed to identify overuse literature with greater specificity and to improve communication of results across disciplines.

Improve institutional review boards' understanding of overuse research-Boards need to be made aware of the lack of evidence behind many current medical practices and of the growing body of evidence highlighting deficits in the safety and effectiveness of many others. Without evidence for standard practice, the balance of benefits to risks is such that placebo or no treatment may be acceptable comparisons to standard of care.

Address overuse in guidelines - Guidelines generally recommend when to treat but not when to avoid treatment. Often, guideline recommendations are extrapolated to diseases or patients in which the intervention was never studied (such as patients with complex multimorbidity). ${ }^{659}$ We recommend guidelines include recommendations of when not to test or treat, limitations to existing evidence, and a section on "possibility for overuse." Also of interest is whether "do not do" recommendations might reduce the practice of "defensive medicine."

\section{Funding}

These research agenda items will require creative approaches and determined individuals to better understand, describe, and ultimately improve medical care. Such work will require support. Public agencies such as the US National Institutes of Health, Agency for Healthcare Research and Quality, Patient Centered Outcomes Research Institute, Department of Veterans Affairs, CDC, United Kingdom research councils, European Commission, and Australia's National Health and Medical Research Council should devote a portion of funding towards the study of overuse. Foundations such as Robert Wood Johnson 
Foundation, ABIM Foundation, and the Commonwealth Fund also have an important role supporting novel ideas and initiatives.

\section{Conclusions}

Overuse of medical care is an increasingly recognized problem that affects costs and patient safety and satisfaction.

Standardizing terms such as overdiagnosis and overtreatment, campaigns such as Choosing Wisely, and journal sections focused on overuse, including those by The BMJ (www.bmj. com/too-much-medicine), JAMA, ${ }^{17}$ and Annals of Internal Medicine ${ }^{16}$ are helping build awareness. The priorities for future research include developing public agencies to monitor overuse; defining the scope of overuse as well as physical and psychological harms; evaluating the effect of Choosing Wisely and other efforts to curb overuse; improving understanding of overuse by review boards and guidelines panels; and adopting standard terminology for library search engines. With concerted research efforts, the coming years could greatly improve our knowledge of overuse to maximize the benefits of medical care.

We thank Lisa Pineles and Lindsay Croft for editorial assistance. We thank the Robert Wood Johnson Foundation who contributed funding support for the 2013 Lown Institute conference where this workshop, chaired by AGE and attended by all authors, took place. The views presented here are those of the authors and do not reflect those of the funders, including their officers and staff.

Contributors and sources: This article derives from a working group of clinicians and researchers in Boston convened by the Lown Institute in December 2013 to develop a research agenda for medical overuse.

Competing interests: We have read and understood BMJ policy on declaration of interests and declare the following interests: DJM received research support from the VA Health Services Research (CRE 12-307), Agency for Healthcare Research and Quality (AHRQ) (K08- HS18111). He has consulted for Welch Allyn for research development and provided self developed lecture in a $3 \mathrm{M}$ sponsored series. NRK received support from a VA Health Services Research and Development Senior Research Career Scientist Award (RCS 02-066). AGE receives salary support as the HCF Research Foundation principal research fellow and holds an Australian NHMRC Sidney Sax fellowship (ID 627061). He receives consulting/sitting fees from Cancer Australia, the Capital Markets Cooperative Research Centre-Health Quality Program, NPS MedicineWise (facilitator of Choosing Wisely Australia), and the Australian Commission on Safety and Quality in Health Care and is appointed to the Medicare Benefits Schedule Reviews Taskforce.

Provenance and peer review: Not commissioned; externally peer reviewed.

1 Deyo RA, Patrick DL. Hope or hype: the obsession with medical advances and the high cost of false promises. AMACOM, American Management Association, 2005.

2 Welch HG, Schwartz L, Woloshin S. Overdiagnosed: Making people sick in the pursuit of health. Beacon Press, 2012

3 Kale MS, Bishop TF, Federman AD, Keyhani S. Trends in the overuse of ambulatory health care services in the United States. JAMA Intern Med 2013;173:142-8.

4 Brownlee S. Overtreated: why too much medicine is making us sicker and poorer. Bloomsbury, 2008

5 Wennberg JE, Fisher ES, Skinner JS. Geography and the debate over Medicare reform. Health Aff (Millwood) 2002;(suppl):w96-114.

6 Schoen C, Osborn R, Doty MM, Bishop M, Peugh J, Murukutla N. Toward higher-performance health systems: adults' health care experiences in seven countries, 2007. Health Aff (Millwood) 2007;26:w717-34

Smith R. Where is the wisdom? BMJ 1991;303:798-9.

8 Chassin MR. Is health care ready for six sigma quality? Milbank Q 1998:76:565-91, 510.

9 Berwick DM, Hackbarth AD. Eliminating waste in US health care. JAMA 2012;307:1513-6.

10 Fisher ES, Wennberg DE, Stukel TA, Gottlieb DJ, Lucas FL, Pinder EL. The implications of regional variations in Medicare spending. Part 2: health outcomes and satisfaction with care. Ann Intern Med 2003;138:288-98.

11 Mold JW, Stein HF. The cascade effect in the clinical care of patients. N Engl J Med 1986;314:512-4.

12 Garvin JS, Rostenberg A Jr, Spellberg MA, Waddington HK. Overtreatment as a cause of disease; a symposium. III Med J 1955;107:171-3.
13 Morden NE, Colla CH, Sequist TD, Rosenthal MB. Choosing wisely-the politics and economics of labeling low-value services. N Engl J Med 2014:370:589-92.

14 American College of Physicians. High value care. http://hvc.acponline.org.

15 Joint Commission and AMA-convened PCPI recommend strategies to minimize overuse. Jt Comm Perspect 2013;33:9-10

16 High value care [collection]. Ann Intern Med http://annals.org/collection.aspx? categoryid $=5999$.

17 Less is more [collection]. JAMA Intern Med http://archinte.jamanetwork.com/collection. aspx?categoryid=6017.

18 Levinson W, Kallewaard M, Bhatia RS, et al. Choosing Wisely: a growing international campaign. BMJ Qual Saf 2015;24:167-74.

19 Buist D, Collado M. Promoting the appropriate use of health care services: research and policy priorities. 2014. www.academyhealth.org/files/HealthCareResourceUse/ ResourceUselssueBrief2014.pdf.

20 Burns M, Dyer M, Bailit M. Reducing overuse and misuse: state strategies to improve quality and cost of health care. Bailit Health Purchasing, 2014

21 Developing a framework and research agenda for overuse and appropriateness measures. Agency for Healthcare Research and Quality Appropriateness Small Conference, 9 June 2009.

22 Coon ER, Quinonez RA, Moyer VA, Schroeder AR. Overdiagnosis: how our compulsion for diagnosis may be harming children. Pediatrics 2014;134:1013-23.

23 Korenstein D, Falk R, Howell EA, Bishop T, Keyhani S. Overuse of health care services in the United States: an understudied problem. Arch Intern Med 2012;172:171-8.

24 Institute of Medicine. Crossing the quality chasm: a new health system for the 21 st century. IoM, 2001.

25 Carter SM, Rogers W, Heath I, Degeling C, Doust J, Barratt A. The challenge of overdiagnosis begins with its definition. BMJ 2015;350:h869.

26 Morgan DJ, Wright SM, Dhruva S. Update on medical overuse. JAMA Intern Med 2015;175:120-4.

27 Sirovich BE, Woloshin S, Schwartz LM. Too little? too much? primary care physicians views on US health care: a brief report. Arch Intern Med 2011;171:1582-5.

28 PerryUndem Research/Communication. Unnecessary tests and procedures in the health care system. 2014. www.choosingwisely.org/wp-content/uploads/2015/04/Final-ChoosingWisely-Survey-Report.pdf.

29 Schwartz AL, Landon BE, Elshaug AG, Chernew ME, McWilliams JM. Measuring low-value care in medicare. JAMA Intern Med 2014;174:1067-76.

30 McCulloch P, Nagendran M, Campbell WB, et al. Strategies to reduce variation in the use of surgery. Lancet 2013;382:1130-9.

31 Birkmeyer JD, Reames BN, McCulloch P, Carr AJ, Campbell WB, Wennberg JE. Understanding of regional variation in the use of surgery. Lancet 2013;382:1121-9.

32 Fisher E, Goodman D, Skinner J, Bronner K. Healthcare spending, quality and outcomes. 2009. www.dartmouthatlas.org/downloads/reports/Spending_Brief_022709.pdf.

33 Fisher ES, Wennberg DE, Stukel TA, Gottlieb DJ, Lucas FL, Pinder EL. The implications of regional variations in Medicare spending. Part 1: the content, quality, and accessibility of care. Ann Intern Med 2003;138:273-87.

34 Welch HG, Sharp SM, Gottlieb DJ, Skinner JS, Wennberg JE. Geographic variation in diagnosis frequency and risk of death among Medicare beneficiaries. JAMA 2011;305:1113-8

35 Song Y, Skinner J, Bynum J, Sutherland J, Wennberg JE, Fisher ES. Regional variations in diagnostic practices. N Engl J Med 2010;363:45-53.

36 Keyhani S, Siu AL. The underuse of overuse research. Health Serv Res 2008:43:1923-30.

37 Howell MD, Novack V, Grgurich P, et al. latrogenic gastric acid suppression and the risk of nosocomial Clostridium difficile infection. Arch Intern Med 2010;170:784-90.

38 Peul WC, van Houwelingen HC, van den Hout WB, et al. Surgery versus prolonged conservative treatment for sciatica. N Engl J Med 2007;356:2245-56.

39 Rossouw JE, Anderson GL, Prentice RL, et al. Risks and benefits of estrogen plus progestin in healthy postmenopausal women: principal results from the Women's Health Initiative randomized controlled trial. JAMA 2002;288:321-33.

40 Elshaug AG, McWilliams JM, Landon BE. The value of low-value lists. JAMA 2013;309:775-6.

41 Hannan EL, Samadashvili Z, Cozzens K, et al. Appropriateness of diagnostic catheterization for suspected coronary artery disease in New York State. Circ Cardiovasc Interv 2014:7:19-27.

42 Prasad V, Vandross A, Toomey C, et al. A decade of reversal: an analysis of 146 contradicted medical practices. Mayo Clin Proc 2013;88:790-8.

43 Carter JL, Coletti RJ, Harris RP. Quantifying and monitoring overdiagnosis in cancer screening: a systematic review of methods. BMJ 2015;350:g7773.

44 Foy AJ, Filippone EJ. The case for intervention bias in the practice of medicine. Yale $J$ Biol Med 2013;86:271-80.

45 Emanuel EJ, Fuchs VR. The perfect storm of overutilization. JAMA 2008:299:2789-91.

46 Mangione-Smith R, McGlynn EA, Elliott MN, Krogstad P, Brook RH. The relationship between perceived parental expectations and pediatrician antimicrobial prescribing behavior. Pediatrics 1999;103:711-8.

47 Natale JE, Joseph JG, Rogers AJ, et al. Cranial computed tomography use among children with minor blunt head trauma: association with race/ethnicity. Arch Pediatr Adolesc Med 2012;166:732-7.

48 Why improving access to health care does not save money. New York Times 2014 Jul 15. www.nytimes.com/2014/07/15/upshot/why-improving-access-to-health-care-does-notsave-money.html?_r=1\&abt=0002\&abg=1.

49 Wiener RS, Schwartz LM, Woloshin S. When a test is too good: how CT pulmonary angiograms find pulmonary emboli that do not need to be found. BMJ 2013;347:f3368.

50 Fisher ES, Wennberg JE, Stukel TA, et al. Associations among hospital capacity, utilization, and mortality of US Medicare beneficiaries, controlling for sociodemographic factors. Health Serv Res 2000;34:1351-62

51 Keyhani S, Falk R, Howell EA, Bishop T, Korenstein D. Overuse and systems of care: a systematic review. Med Care 2013;51:503-8.

52 Smith AK, White DB, Arnold RM. Uncertainty-the other side of prognosis. N Engl J Med 2013;368:2448-50.

53 Mulley AG, Trimble C, Elwyn G. Stop the silent misdiagnosis: patients' preferences matter. BMJ 2012;345:e6572.

54 Wennberg JE, Fisher ES, Stukel TA, Skinner JS, Sharp SM, Bronner KK. Use of hospitals, physician visits, and hospice care during last six months of life among cohorts loyal to highly respected hospitals in the United States. BMJ 2004;328:607. 


\section{Key messages}

Research into the effects of overuse in medicine is uncoordinated More research is needed to define the extent of overuse and its harms Adoption of standard terminology is essential to better understanding Public agencies are needed to monitor overuse Evaluation of current efforts to curb overuse is also a priority

55 Parker L, Levin DC, Frangos A, Rao VM. Geographic variation in the utilization of noninvasive diagnostic imaging: national medicare data, 1998-2007. AJR Am J Roentgenol 2010;194:1034-9.

56 Bragg F, Cromwell DA, Edozien LC, et al. Variation in rates of caesarean section among English NHS trusts after accounting for maternal and clinical risk: cross sectional study. BMJ 2010;341:c5065.

57 Wachter RM, Flanders SA, Fee C, Pronovost PJ. Public reporting of antibiotic timing in patients with pneumonia: lessons from a flawed performance measure. Ann Intern Med 2008;149:29-32.

58 Dickersin $\mathrm{K}$. The existence of publication bias and risk factors for its occurrence. JAMA 1990;263:1385-9.

59 Djulbegovic B, Paul A. From efficacy to effectiveness in the face of uncertainty: indication creep and prevention creep. JAMA 2011;305:2005-6.

60 Pencina MJ, Navar-Boggan AM, D'Agostino RBS, et al. Application of new cholesterol guidelines to a population-based sample. N Engl J Med 2014;370:1422-31.

61 Lenzer J. Majority of panelists on controversial new cholesterol guideline have current or recent ties to drug manufacturers. BMJ 2013;347:f6989.

62 Guyatt GH, Oxman AD, Vist GE, et al. GRADE: an emerging consensus on rating quality of evidence and strength of recommendations. BMJ 2008;336:924-6.

63 Leape LL, Berwick DM, Bates DW. What practices will most improve safety? Evidence-based medicine meets patient safety. JAMA 2002;288:501-7.

64 Kachalia A, Berg A, Fagerlin A, et al. Overuse of testing in preoperative evaluation and syncope: a survey of hospitalists. Ann Intern Med 2015;162:100-8.

65 Greenhalgh T, Howick J, Maskrey N, Evidence Based Medicine Renaissance Group. Evidence based medicine: a movement in crisis? BMJ 2014;348:g3725

66 Kalager M, Adami HO, Bretthauer M, Tamimi RM. Overdiagnosis of invasive breast cance due to mammography screening: results from the Norwegian screening program. Ann Intern Med 2012;156:491-9.

67 Blendon RJ, Benson JM. The public and the conflict over future Medicare spending. $N$ Engl J Med 2013;369:1066-73.

68 Esserman LJ, Thompson IM Jr, Reid B. Overdiagnosis and overtreatment in cancer: an opportunity for improvement. JAMA 2013;310:797-8.

69 Yong PL, Saunders RS, Olsen L. The healthcare imperative: lowering costs and improving outcomes . 2011. www.ncbi.nlm.nih.gov/books/NBK53920/

70 May CR, Eton DT, Boehmer K, et al. Rethinking the patient: using burden of treatment theory to understand the changing dynamics of illness. BMC Health Serv Res 2014;281:6963-14-281.

71 Mair FS, May CR. Thinking about the burden of treatment. BMJ 2014;349:g6680.

72 Fiks AG, Mayne S, Localio AR, Alessandrini EA, Guevara JP. Shared decision-making and health care expenditures among children with special health care needs. Pediatrics 2012;129:99-107.

73 Omer ZB, Hwang ES, Esserman LJ, Howe R, Ozanne EM. Impact of ductal carcinoma in situ terminology on patient treatment preferences. JAMA Intern Med 2013;173:1830-1.
74 Man-Son-Hing M, Laupacis A, O'Connor AM, et al. A patient decision aid regarding antithrombotic therapy for stroke prevention in atrial fibrillation: a randomized controlled trial. JAMA 1999;282:737-43.

75 Volk RJ, Cass AR, Spann SJ. A randomized controlled trial of shared decision making for prostate cancer screening. Arch Fam Med 1999;8:333-40.

76 James PA, Oparil S, Carter BL, et al. 2014 evidence-based guideline for the management of high blood pressure in adults: report from the panel members appointed to the Eighth Joint National Committee (JNC 8). JAMA 2014:311:507-20.

77 Hooton TM, Bradley SF, Cardenas DD, et al. Diagnosis, prevention, and treatment of catheter-associated urinary tract infection in adults: 2009 international clinical practice guidelines from the Infectious Diseases Society of America. Clin Infect Dis 2010;50:625-63.

78 Elshaug AG. Over 150 potentially low-value health care practices: an Australian study. Reply. Med J Aust 2013;198:597-8.

79 NNT Groups. Quick summaries of evidence-based medicine. www.thennt.com.

80 Health Quality Ontario. Vitamin D testing. www.hqontario.ca/evidence/publications-andohtac-recommendations/maps-project/vitamin-d-testing.

81 Evans WK, Laupacis A, Gulenchyn KY, Levin L, Levine M. Evidence-based approach to the introduction of positron emission tomography in Ontario, Canada. $J$ Clin Oncol 2009;27:5607-13.

82 Ahn HS, Kim HJ, Welch HG. Korea's thyroid-cancer "epidemic"-screening and overdiagnosis. N Engl J Med 2014:371:1765-7.

83 Cornell J, Mulrow CD, Localio AR. Diagnostic test accuracy and clinical decision making. Ann Intern Med 2008;149:904-6.

84 Kroenke K. A practical and evidence-based approach to common symptoms: a narrative review. Ann Intern Med 2014;161:579-86.

85 Siontis KC, Siontis GC, Contopoulos-loannidis DG, loannidis JP. Diagnostic tests often fail to lead to changes in patient outcomes. J Clin Epidemiol 2014;67:612-21.

86 Haines T, O'Brien L, McDermott F, et al. A novel research design can aid disinvestment from existing health technologies with uncertain effectiveness, cost-effectiveness, and/or safety. J Clin Epidemiol 2014;67:144-51.

87 Scott IA, Elshaug AG. Foregoing low-value care: how much evidence is needed to change beliefs? Intern Med J 2013;43:107-9.

88 Brewer NT, Salz T, Lillie SE. Systematic review: the long-term effects of false-positive mammograms. Ann Intern Med 2007;146:502-10.

89 Elshaug AG. Over 150 potentially low-value health care practices: an Australian study. Med J Aust 2013;198:85.

90 Boyd CM, Darer J, Boult C, Fried LP, Boult L, Wu AW. Clinical practice guidelines and quality of care for older patients with multiple comorbid diseases: implications for pay for performance. JAMA 2005;294:716-24.

Accepted: 30 July 2015

Cite this as: BMJ 2015;351:h4534

(c) BMJ Publishing Group Ltd 2015 


\section{Table}

Table 1/ Provider and patient factors identified as causing overuse of medical care

\begin{tabular}{|c|c|}
\hline Intrinsic & Extrinsic \\
\hline \multicolumn{2}{|l|}{ Provider driven } \\
\hline Belief more care is better ${ }^{7647}$ & Financial—provider ${ }^{45}$ and hospital ${ }^{323348}$ \\
\hline Lack of knowledge of harm from overuse ${ }^{2649}$ & Resource supply ${ }^{50}$ \\
\hline Discomfort with uncertainty ${ }^{4445495152}$ & Defensive medicine $^{128}$ \\
\hline Poor knowledge of patient preference ${ }^{53}$ & Variation in medical and surgical practice ${ }^{545556}$ \\
\hline \multirow[t]{2}{*}{ Regret for errors of omission greater than commission ${ }^{2845}$} & Process measures ${ }^{57}$ \\
\hline & Inadequate time ${ }^{12728}$ \\
\hline Belief action better than inaction ${ }^{28,52}$ & Positive publication bias ${ }^{44455}$ \\
\hline Use of therapeutics "off label" & Guidelines promoting overuse $\mathrm{e}^{606162}$ \\
\hline \multirow[t]{2}{*}{ Over-reliance on pathophysiological and anatomical reasoning } & Medical culture $\mathrm{C}^{63}$ \\
\hline & Lack of training in shared decision making ${ }^{1}$ \\
\hline \multirow[t]{2}{*}{ Desire for reassurance ${ }^{64}$} & Advocacy groups $^{1}$ \\
\hline & Medicalization of non-disease (eg, baldness) ${ }^{14865}$ \\
\hline \multicolumn{2}{|l|}{ Patient driven } \\
\hline Belief more care is better ${ }^{7647}$ & Financial-third party payment shielding from costs ${ }^{145}$ \\
\hline \multicolumn{2}{|l|}{ Lack of knowledge of harm from overuse ${ }^{1}$} \\
\hline \multirow[t]{4}{*}{ Discomfort with uncertainty ${ }^{147}$} & Culture of avoiding mortality ${ }^{1}$ \\
\hline & Media misrepresentation of research ${ }^{1}$ \\
\hline & Advocacy groups $^{1}$ \\
\hline & Medicalization of non-disease (eg, baldness) ${ }^{14866}$ \\
\hline
\end{tabular}




\section{Figure}

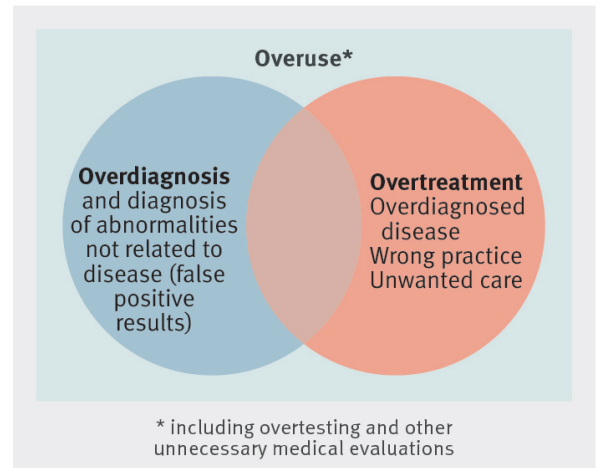

Fig 1 Relation between overdiagnosis, overtreatment, and overuse 